\title{
Reflections on 20 years of RNA folding, dynamics, and structure
}

RICK RUSSELL

Department of Molecular Biosciences and the Institute for Cellular and Molecular Biology, University of Texas at Austin, Austin, Texas 78712, USA

First I should confess that I haven't officially been part of the "RNA world" for a full two decades. In 1995, I was a graduate student studying protein chaperones and wondering what I might do when I finished, and I didn't enter the RNA field until two years later as a postdoc in Dan Herschlag's lab. Nevertheless, with that as a starting point, I feel competent to reflect on important milestones in our understanding of RNA structure and folding in the last two decades. What follows is not at all meant to be a complete list but is connected to specific memories that have stuck with me, and I apologize in advance to colleagues whose contributions have been omitted because of space constraints or memory limitations.

Overall, it is not a stretch to say that the progress has been transformative. In 1995, little was known about the three-dimensional structures of complex RNAs, and even less about how they fold into these structures. Insightful uses of chemical footprinting and comparative sequence analysis in the early 1990s gave insights into the general architecture of the catalytic group I and group II intron RNAs, including the notion of modular tertiary contact motifs, and even a 3D model of the group I intron core. Still, we knew little about how RNA helices are packed together into globular structures and, with the notable exception of tRNA, crystal structures of folded, functional RNAs were lacking. Indeed, the one catalytic RNA for which there was a crystal structure, the hammerhead ribozyme, didn't look like a structured RNA; the two helices that we now know pack together to form its active site lay separated, splayed open, in the absence of a key tertiary contact that was deleted in an effort to isolate the minimal ribozyme.

In 1995, the field of higher-order RNA folding was also at a very early stage, one in which it was possible to read essentially every paper on the topic. There were two that I found particularly exciting. The first, published in 1994 from the Williamson group, used a clever assay involving hybridization of complementary oligonucleotides to monitor structure formation of a group I intron ribozyme. This work showed clearly the presence of kinetic folding intermediates, solidify-

\footnotetext{
Corresponding author: rick_russell@cm.utexas.edu

Article and publication date are at http://www.rnajournal.org/cgi/doi/ 10.1261/rna.050781.115. Freely available online through the RNA Open Access option.
}

ing an emerging view of RNA folding as a multi-step process, and it showed that different regions of the RNA became structured with rate constants spanning at least two orders of magnitude. The second paper was a short review by Herschlag that took the idea of RNA folding intermediates a step further and postulated the existence of RNA chaperones, proteins that would promote native folding of structured RNAs and/or accelerate RNA conformational transitions. It was known that some positively charged proteins could accelerate RNA structural transitions in vitro, but at the time it was not clear that any of these proteins truly functioned as RNA chaperones. Further, this review suggested that RNA "helicase" proteins from the DEAD-box family, which were known to function in the context of structured RNAs including the spliceosome, might function as chaperones and create a parallel world to the many ATP-dependent chaperones of protein folding.

Over the next several years as a postdoc (1997-2002), I was thrilled to witness tremendous advances in RNA folding and structure. In 1998, I hung on every word of a paper from the Woodson, Brenowitz, and Chance groups that described development and implementation of a time-resolved footprinting method that could detect RNA folding intermediates on the time scale of milliseconds. In addition to expanding the time range over which RNA tertiary structure was known to form, this paper ushered in chemical footprinting as a central method for following time-resolved structure formation in RNAs. At about the same time, work from several groups showed that for several RNAs, native folding requires the transient disruption of structure, implying that at least some of the detected intermediates represent misfolded structures.

As a postdoc I was fortunate to witness first hand some important advances and sometimes even contribute to them. A great thing about Stanford was how easy it was to start terrific collaborations, and the start of one is firmly etched in my mind. I was at the bench loading a seemingly endless row of denaturing gels (a near-universal memory of Herschlag lab alums) when Dan strode into the lab and said something like, "We really need to talk to Steve Chu about his single

(C) 2015 Russell This article, published in $R N A$, is available under a Creative Commons License (Attribution-NonCommercial 4.0 International), as described at http://creativecommons.org/licenses/by-nc/4.0/. 
molecule fluorescence methods.” As I recall, my response was something like, "Whatcha talkin' 'bout, Dan?" Fast forward a few months and two or three meetings between the labs, and I was gathered around a microscope with a spectacular (and spectacularly collaborative) group of students and postdocs taking turns looking at immobilized ribozyme molecules. Beyond being incredibly cool, it was clear that single molecule methods could open up new frontiers in understanding molecular behavior in complex processes. At the most general level, we reasoned that following individual molecules allows one to detect and study intermediates that do not accumulate, whether it's because of multiple pathways or heterogeneity, loss of synchrony in repetitive processes like polymerization, or just an irreversible slow step that is followed by a fast step. Indeed, 15 years later single molecule methods are fairly routine and have been used to extend our understanding of the many conformations achievable for numerous structured RNAs and RNA-protein complexes, and the complex transitions that underlie exchange of these conformations.

A key venue for exciting memories is the annual RNA Society meeting, which I've attended many times starting in 1998 (my abstract book collection indicates 11). The many exciting things that I've learned from talks, posters, and chats with colleagues and students are much too numerous to detail. An especially vivid memory is from the 2000 meeting in Madison, WI. The opening session was titled, "Ribosomes and RNA-protein interactions" and I recall a group of us settling into our seats with eager anticipation for several talks on the unpublished structures of the ribosomal subunits. We were not at all disappointed; the structures that were presented that evening were amazing, like nothing we had seen previously in size and complexity. For reasons that I can't quite recall, the session went late into the night, yet we remained perched on the edge of our seats, looking in awe at these structures that would change the way we viewed both the ribosome and RNA-protein complexes in general. In addition to the wealth of structural details and novel arrangements of RNA and protein, the large subunit structure told us a lot about how the ribosome joins amino acids. First, the complete absence of proteins ended any remaining debate about whether the ribosome is a ribozyme. The structure and additional work also indicated a lack of divalent cations in peptide bond formation, and concurrent work on other RNAs showed that divalent ions are not universally necessary for RNA folding or even for catalysis. It seems to be a recurring pattern that RNA defies expectations about its capabilities.

In the last 10 to 15 years, three discoveries stand out in my mind. The first is the discovery of riboswitches by Breaker and colleagues, "nature's aptamers." Beyond being a demonstration that if a biomolecule possesses a talent in vitro, nature will likely have exploited that talent, the discovery of riboswitches dramatically broadened the scope of structured RNAs. Second was the demonstration that RNA helicase proteins indeed function as chaperones. I also learned about this work at the RNA Society meeting, this time in Banff in 2001 in a talk from the Lambowitz group. Understanding how these proteins promote RNA folding transitions then emerged as a central question that has occupied my lab and others. We have yet to understand the scope of these proteins' effects in vivo, and I was thrilled to read recent work from Weissman's group in which high-throughput footprinting and next-generation sequencing (the latter method obviously a major revolution in all aspects of RNA biology) revealed that RNAs tend to be less structured than they are in vitro, and this difference requires ATP and therefore most likely involves ATPase proteins. Third, the fields of RNA structure and function have been broadened yet again by the discovery of extensive transcription beyond known protein-coding genes, exposing massive numbers of apparently noncoding RNAs and opening yet more vast fields of RNA research.

Since 1995, the fields of RNA structure and folding have matured, broadened, and truly transformed. Still, huge challenges remain. It is still not possible to reliably predict the tertiary structure of even a relatively small RNA from its sequence, much less predict the folding pathways, intermediates, or the transiently populated "excited states" that can result from dynamic fluctuations of the native structure. In addition, with the knowledge of pervasive transcription comes a new frontier. While some of these RNAs may have defined structures, many of them lack stable tertiary structure, instead probably shape shifting as they interact with partner molecules. Thus, further leaps in the depth of our understanding of RNA structure formation and dynamics will ultimately be necessary to understand the vast range of functional RNA conformations and their biological roles. 

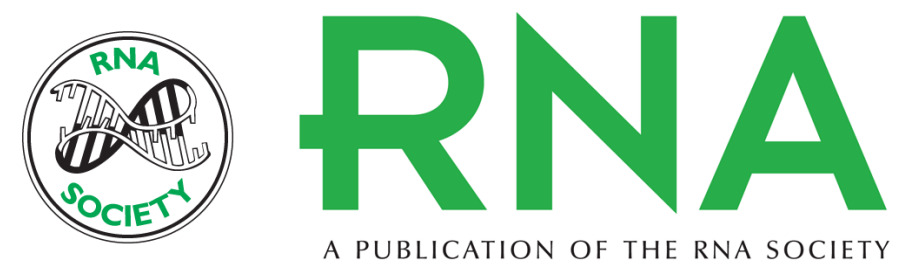

A PUBLICATION OF THE RNA SOCIETY

\section{Reflections on 20 years of RNA folding, dynamics, and structure}

Rick Russell

RNA 2015 21: 723-724

Open Access Freely available online through the RNA Open Access option.

Creative This article, published in RNA, is available under a Creative Commons License Commons (Attribution-NonCommercial 4.0 International), as described at

License http://creativecommons.org/licenses/by-nc/4.0/.

Email Alerting Receive free email alerts when new articles cite this article - sign up in the box at the Service top right corner of the article or click here.

To subscribe to $R N A$ go to:

http://rnajournal.cshlp.org/subscriptions

(C) 2015 Russell; Published by Cold Spring Harbor Laboratory Press for the RNA Society 